\title{
Polymorphic DNA microsatellite markers for forensic individual identification and parentage analyses of seven threatened species of parrots (family Psittacidae)
}

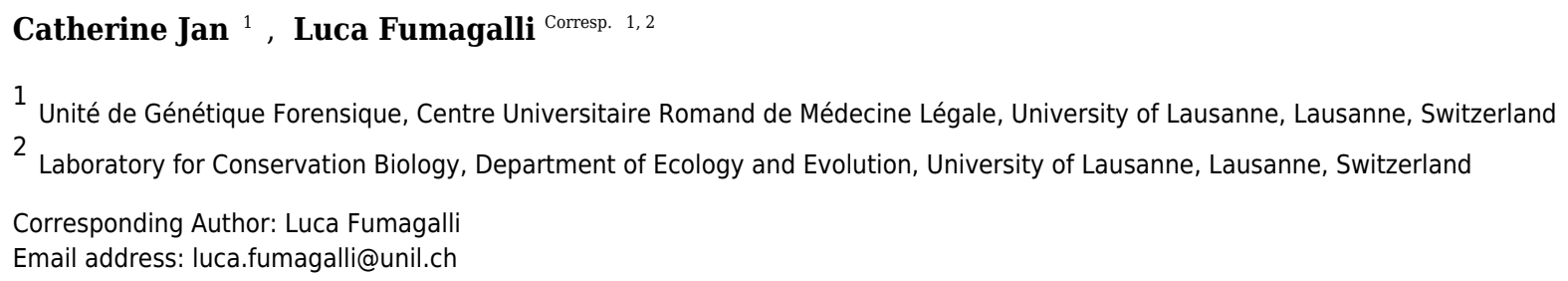

The parrot family represents one of the bird group with the largest number of endangered species, as a result of habitat destruction and illegal trade. This illicit traffic involves the smuggling of eggs and animals, and the laundering through captive breeding facilities of wild-caught animals. Despite the huge potential of wildlife DNA forensics to determine with conclusive evidence illegal trade, current usage of DNA profiling approaches in parrots has been limited by the lack of suitable molecular markers specifically developed for the focal species and by low cross-species polymorphism. In this study, we isolated DNA microsatellite markers in seven parrot species threatened with extinction (Amazona brasiliensis, A. oratrix, A. pretrei, A. rhodocorytha, Anodorhynchus leari, Ara rubrogenys and Primolius couloni). From an enriched genomic library followed by 454 pyrosequencing, we characterized a total of 106 polymorphic microsatellite markers (mostly tetranucleotides) in the seven species and tested them across an average number of 19 individuals per species. The mean number of alleles per species and across loci varied from 6.4 to 8.3, with the mean observed heterozygosities ranging from 0.65 to 0.84 . Identity and parentage exclusion probabilities were highly discriminatory. The high variability displayed by these microsatellite loci demonstrates their potential utility to perform individual genotyping and parentage analyses, in order to develop a DNA testing framework to determine illegal traffic in these threatened species. 
1 Polymorphic DNA microsatellite markers for forensic individual identification and 2 parentage analyses of seven threatened species of parrots (family Psittacidae)

3 Catherine $\mathrm{JAN}^{1}$ and Luca FUMAGALLI ${ }^{1,2}$

$4{ }^{1}$ Unité de Génétique Forensique, Centre Universitaire Romand de Médecine Légale, Ch. de la

5 Vulliette 4, CH-1000 Lausanne 25 (Switzerland)

$6{ }^{2}$ Laboratory for Conservation Biology, Department of Ecology and Evolution, Biophore,

7 University of Lausanne, $\mathrm{CH}-1015$ Lausanne (Switzerland)

8

9

10

11

12

13

14

15

16

17

18 Corresponding author :

Luca Fumagalli, luca.fumagalli@unil.ch

20

21

22

23 


\section{ABSTRACT}

26 The parrot family represents one of the bird group with the largest number of endangered 27 species, as a result of habitat destruction and illegal trade. This illicit traffic involves the 28 smuggling of eggs and animals, and the laundering through captive breeding facilities of wild29 caught animals. Despite the huge potential of wildlife DNA forensics to determine with conclusive evidence illegal trade, current usage of DNA profiling approaches in parrots has been limited by the lack of suitable molecular markers specifically developed for the focal species and by low cross-species polymorphism. In this study, we isolated DNA microsatellite markers in seven parrot species threatened with extinction (Amazona brasiliensis, A. oratrix, A. pretrei, A. rhodocorytha, Anodorhynchus leari, Ara rubrogenys and Primolius couloni). From an enriched genomic library followed by 454 pyrosequencing, we characterized a total of 106 polymorphic microsatellite markers (mostly tetranucleotides) in the seven species and tested them across an average number of 19 individuals per species. The mean number of alleles per species and across loci varied from 6.4 to 8.3 , with the mean observed heterozygosities ranging from 0.65 to 0.80 . Identity and parentage exclusion probabilities were highly discriminatory. The high variability displayed by these microsatellite loci demonstrates their potential utility to perform individual genotyping and parentage analyses, in order to develop a DNA testing framework to determine illegal traffic in these threatened species. 


\section{INTRODUCTION}

45 Poaching, i.e. illegal harvesting, trade, transport, possession and use of wildlife, is among the

46

47

48

49

50

51

52

53

54

55

56

57

most serious threats to the persistence of many endangered species, and represents in profits one of the world's largest illegal trafficking (Haken 2011; South \& Wyatt 2011). Wildlife DNA forensics deals with the genetic identification of illegal trade in endangered animal and plant species. Because of powerful and unambiguous identification, and the possibility to use very small (and even degraded) DNA samples from various sources (e.g. tissue, scats, hair, feathers, eggshells), molecular techniques have become increasingly important in the detection of illegal hunting and traffic of wildlife. This relatively recent discipline is now becoming a key investigative tool to fight wildlife crime and assist law enforcement and wildlife management agencies (reviewed in (Iyengar 2014; Johnson et al. 2014; Ogden et al. 2010).

Wild birds in general and Neotropical parrots (family Psittacidae) in particular are highly prized by collectors for their colourful plumage, mimicry ability, exotic appeal and rarity. The Psittacidae family contain over 370 species worldwide, including parrots, macaws, amazons, cockatoos (Collar 1997). Habitat loss in combination with illegal trade are a significant threat to these species. According to the IUCN Red List of Threatened Species, 101 of the world's parrot species are considered to be threatened with extinction (IUCN 2015). Almost all of the world's parrot species are protected by the Convention on International Trade in Endangered Species of Wild Fauna and Flora (CITES), with over 40 species being listed on CITES Appendix I, the Convention's highest level of protection. All other parrots (excluding three species) are listed in Appendix II, which regulates commercial trade through a permitting system (UNEP-WCMC 2015). The illicit trade in parrots involves both the smuggling of eggs and live animals from the wild and the falsification of documents. 
67 Captive breeding is one of the primary activities for the production of animals of commercial 68 value, in particular for many endangered parrot species. This creates the possibility that 69 individuals are taken from the wild illegally and laundered through captive breeding facilities by 70 claiming them to be legitimate progeny of already captive individuals. Parentage verification 71 using high-resolution markers such as DNA microsatellites can establish without ambiguity 72 whether a claim of parentage is true, and therefore provide the ultimate evidence of illegal 73 activity.

74 Despite the potential of wildlife DNA forensics to determine with conclusive evidence illegal 75 trade or harvest from the wild, the implementation of such analyses in parrots has been very 76 limited to date for different reasons. First, the number of genetic markers (i.e. microsatellites) 77 specifically developed for the species of interest is low, constraining the use of markers 78 developed in other species (cross-amplification), with a frequent loss in marker specificity and 79 resolution, and therefore loss of statistical power (Presti \& Wasko 2014). Second, success rate in 80 isolating microsatellites from parrots has always been reported as low (Hughes et al. 1998). 81 Third, because of the extreme rarity and therefore difficulty of sampling some species, compiling 82 population DNA databases for the computation of the statistical certainty of a parental 83 assignment is a very difficult and challenging task.

84 Here we report the development and characterization of specific, polymorphic microsatellite 85 loci for seven parrot species which are currently involved in local and international illegal traffic 86 for pet supply, all being threatened with extinction according to the IUCN criteria (IUCN 2015) 87 and CITES-listed in Appendix I. These species comprise the Red-tailed amazon (Amazona 88 brasiliensis), the Yellow-headed amazon (A. oratrix), the Red-spectacled amazon (A. pretrei), 89 the Red-browed amazon (A. rhodocorytha), the Lear's macaw (Anodorhynchus leari), the Red- 
90 fronted macaw (Ara rubrogenys) and the Blue-headed macaw (Primolius couloni). These

91 markers will allow a genetic identification and parentage DNA testing framework to be set up to

92 assist the detection of illegal trade and traffic of these endangered parrot species.

93 


\section{MATERIALS AND METHODS}

95 Total genomic DNA was isolated from blood samples using one individual per species with the

96 DNeasy Blood \& Tissue Kit (Qiagen). To isolate the microsatellite sequences from the genomic

97 DNA extractions, an hybridization enrichment protocol with SSR oligonucleotides (for 98 GATA/GTAT motifs) followed by 454-pyrosequencing was performed by a private company 99 (Ecogenics $\mathrm{GmbH}$, Balgach, Switzerland). The same company designed a list of suitable primer 100 pairs for the seven species with a filtering threshold of 350 base pairs.

101 Blood and feather samples were collected from private and public aviaries in several 102 European countries (see Acknowledgements). DNA extractions were performed using the 103 QIAamp DNA Mini Kit (Qiagen) following the manufacturers' instructions with some 104 modifications. The samples were digested in $180 \mu \mathrm{L}$ ATL buffer and $20-40 \mu \mathrm{L}$ proteinase K, 105 then incubated overnight at $56^{\circ} \mathrm{C}$ using a thermomixer. The lysate was then loaded through a 106 QIAshredder homogenizing column (Qiagen) and centrifuged for $5 \mathrm{~min}$ at 14,000 rpm. All 107 further steps were performed according to the QIAamp kit protocol. In the final step, DNA was 108 eluted in $120-200 \mu \mathrm{L}$ elution buffer and stored at $-20^{\circ} \mathrm{C}$.

109 We tested for amplification and polymorphism about 50 primer pairs per species in a panel of 110 about 5 individuals per species. PCR reactions were performed in a final volume of $21 \mu \mathrm{L}$, 111 containing $1 \mu \mathrm{L}$ of DNA template, 1 unit AmpliTaq Gold (Applied Biosystems), $1 \times$ PCR II 112 buffer, $3.5 \mathrm{mM} \mathrm{MgCl}_{2}, 0.1 \mu \mathrm{M}$ each primer, $0.2 \mathrm{mM}$ each dNTPs, $0.2 \mathrm{mg} / \mathrm{ml} \mathrm{BSA} \mathrm{(Sigma).}$ 113 PCRs were run as follows: an initial denaturation for $10 \mathrm{~min}$ at $95^{\circ} \mathrm{C}$, followed by 35 cycles of $11430 \mathrm{sec}$ at $95{ }^{\circ} \mathrm{C}, 30 \mathrm{sec}$ at $57^{\circ} \mathrm{C}, 45 \mathrm{sec}$ at $72{ }^{\circ} \mathrm{C}$, and final elongation for $30 \mathrm{~min}$ at $72{ }^{\circ} \mathrm{C}$.

115 The forward primer of each primer set was fluorescently labelled with either 6FAM, 116 ATTO532, ATTO550 and ATTO565 (Table S1). Fragment analysis was conducted on an ABI 
1173130 automated sequencer (Applied Biosystems). Alleles were scored using GeneMapper v3.2.1 118 (Applied Biosystems).

119 The number of alleles per locus $(A)$, observed $\left(H_{\mathrm{O}}\right)$ and expected $\left(H_{\mathrm{E}}\right)$ heterozygosities, 120 identity $\left(P_{\mathrm{ID}}\right.$ and $\left.P_{\mathrm{IDsib}}\right)$ and parentage exclusion $(P 1, P 2$ and $P 3)$ probabilities were calculated 121 with GenAlEx software (Peakall \& Smouse 2006); departures from Hardy-Weinberg equilibrium 122 (HWE) at each locus and fixation index Fis were calculated using the sofware FSTAT v2.9.3.2 123 (updated from Goudet (1995)). The presence of null alleles was tested with MICROCHECKER 124 (Van Oosterhout et al. 2004). The Polymorphism Information Content (PIC) was estimated using 125 CERVUS v3.0 (Kalinowski et al. 2007). 


\section{RESULTS AND DISCUSSION}

128 We identified a total of 106 polymorphic microsatellite loci (3 tri-, 103 tetranucleotides) across

129 the seven species. Genetic variation was examined in 14-26 individuals per species. The number

130 of polymophic loci per species varied between 14 and 17. A mean number of 6.4-8.3 alleles per

131 locus were detected across the 106 loci in the seven species. Mean observed and expected

132 heterozygosities ranged from 0.65 to 0.8 and 0.6 to 0.8 , respectively. PIC values were relatively

133 high, ranging between approximately 0.6 and 0.8 in all species. In some species, few loci

134 exhibited departure from HWE (significant Fis) along with the presence of null alleles.

135 Nevertheless, these results must be taken with caution since there is a high likelihood of close

136 relatedness among samples (siblings, captive strains). Therefore, it is not possible to disentangle

137 whether HWE departure results from inbreeding or null alleles. Identity and parentage exclusion

138 probabilities were highly discriminant. In particular, the probability of identity $P_{\text {IDsib }}$ (assuming

139 the presence of siblings) varied from $1.1 \times 10-06$ to $3.3 \times 10-08$ across the seven species. Although

140 based on a relatively small number of samples, these numbers are noteworthy given that most of

141 our parrot individuals originate from aviaries and zoos and are expected to comprise full siblings

142 or related individuals. Parentage exclusion probability when one parent is known $(P 1)$, when

143 genotype of one parent is missing $(P 2)$ and of a pair of individuals as parents $(P 3)$ ranged from

1440.995 to 1 . Results overall loci and per locus are summarized in Table 1 and Table S1, 145 respectively.

146

147

148 Table 1 Characterization of polymorphic microsatellite loci by species in the seven studied 149 parrot taxa (Psittacidae, Aves) with n, number of individuals analyzed; No. loci, number of 
150 loci; Mean $\mathbf{N}$, mean number of alleles over loci; Mean $\boldsymbol{H}_{\mathbf{O}}$, mean observed heterozygosity

151 over loci; Mean $\boldsymbol{H}_{\mathrm{E}}$, mean expected heterozygosity over loci; Fis, fixation index; $\boldsymbol{P}_{\mathrm{ID}}$,

152 probability of identity; $\boldsymbol{P}_{\mathrm{IDsib}}$, sibling probability of identity; $\boldsymbol{P} 1$, probability of parentage

153 exclusion when one parent is known; $\boldsymbol{P} 2$, probability of parentage exclusion when genotype

154 of one parent is missing; $\boldsymbol{P 3}$, probability of parentage exclusion of a pair of individuals as

155 parents. Bold values for Fis indicate significant $(\mathbf{p}<\mathbf{0 . 0 5})$ departure from $\mathrm{HWE}$ after

156 Bonferroni correction.

157

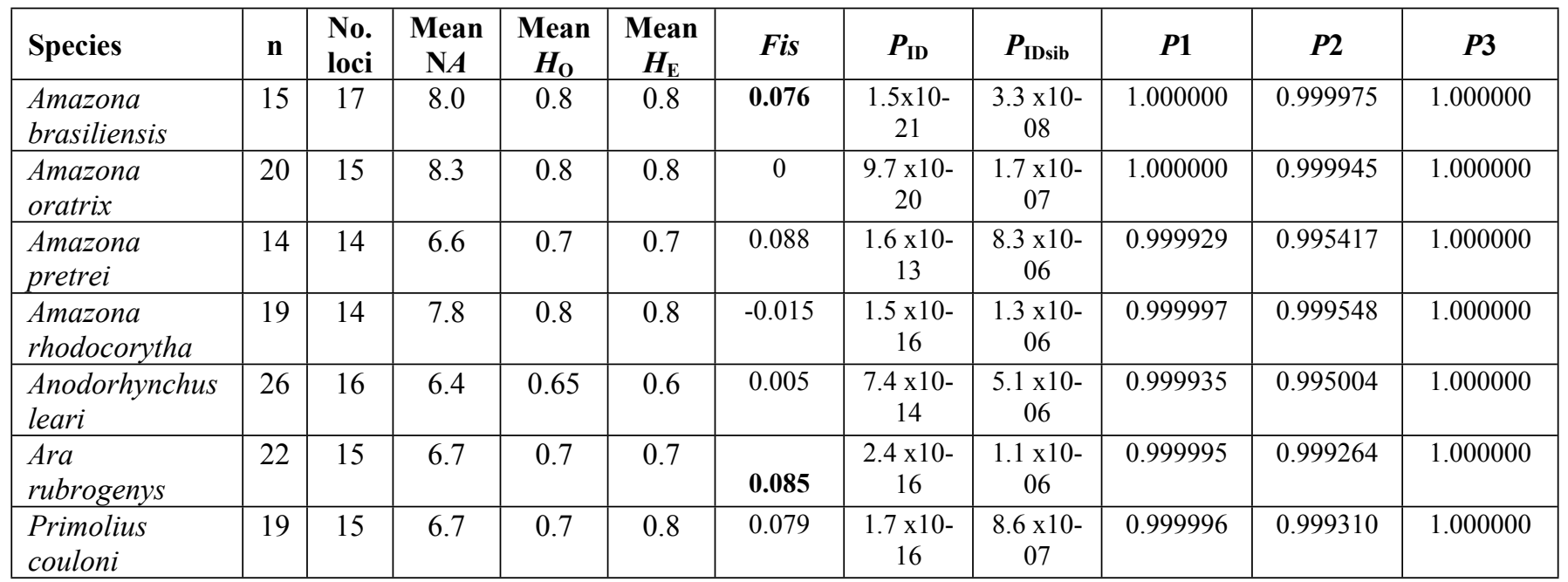

158

159 Without conclusive evidence it is difficult to prosecute illegal trade in wildlife. DNA analysis

160 provides this evidence and can conclusively prove whether birds have or have not been captive

161 bred. Despite its obvious conservation importance, this approach has been so far rarely applied.

162 Ringler (2012) performed a sibship analysis with heterologous (i.e. not species-specific)

163 microsatellite markers in two captive-bred endangered parrot species (Amazona collaria and $A$.

164 agilis), and was able to identify groups of full siblings indicative of whole-nest poaching. In

165 three forensic caseworks involving Australian black-cockatoos (Calyptorhinchus spp.), White et

166 al. (2012) determined illegal harvesting and trade activities with paternity and individual identity 
167 testings. Importantly, the authors established a population genotype database composed of

168 several hundred wild individuals, which is invaluable for statistical inference and methodological

169 compliance (Linacre et al. 2011), but an extremely difficult task when dealing with rare and

170 endangered Neotropical parrot taxa such as those included in the present study (their wild

171 populations being mostly declining and composed by few thousand mature individuals at best;

172 (IUCN 2015)). Finally, Dawnay et al. (2009) validated 28 microsatellite markers (both specific

173 and heterologous) for forensic individual and parentage analyses based on the allele frequencies

174 estimated in wild populations (nr. of individuals: 99-190) of six bird of prey species (families

175 Accipitridae and Falconidae).

176 The data produced in this study has the potential to provide authorities with the ability to 177 investigate suspected poachers and smugglers, investigating false parentage claims or 178 establishing a link between trace evidence and an individual (e.g. in case of stolen birds, or when 179 a bird is illegally transferred between different locations). In addition, these markers can be used 180 to implement accurate assessments of relatedness among individuals, which is a crucial issue in 181 captive programs when establishing optimal breeding protocols to preserve genetic variation and 182 minimize inbreeding.

183 In summary, we have developed and characterized microsatellite markers for seven 184 Neotropical parrots threatened with extinction. These markers are able to provide robust and 185 highly discriminatory DNA forensic evidence for identification and parentage analyses. They can 186 be used to detect illegal trade and captive laundering of wild birds, and more generally should 187 promote population-level analyses and conservation efforts in these threatened species. 


\section{ACKNOWLEDGEMENTS}

189

190 We would like to thank M. Lörtscher, B. Mainini and M. Walker (Federal Food Safety and

191 Veterinary Office, Bern, Switzerland) for their precious collaboration during this study. Samples

192 were kindly provided by C. Y. Miyaki (Sao Paulo University, Brazil); Loro Parque Fundacion

193 (Tenerife, Spain); Dortmund Zoo, Tierpark Berlin, Wuppertal Zoo (Germany); ZooParc de

194 Beauval, Bioparc de Doué la Fontaine (France); Tiergarten Walding (Austria). J. Schneider, C.

195 Dufresnes and A. Duplan helped for sampling, labwork and analyses. 
196

197

198

199

200

201

202

203

204

205

206

207

208

209

210

211

212

213

214

215

216

217

218

219

220

221

222

223

224

225

226

227

228

229

230

231

232

233

234

235

236

237

238

239

240

\section{REFERENCES}

Collar NJ. 1997. Family Psittacidae (Parrots). In: Del Hoyo J, Elliot AE, and Sargatal J, eds. Handbook of the Birds of the World. Barcelona, Spain: Lynx Edicions.

Dawnay N, Ogden R, Wetton JH, Thorpe RS, and McEwing R. 2009. Genetic data from 28 STR loci for forensic individual identification and parentage analyses in 6 bird of prey species. Forensic Science International-Genetics 3:E63-E69. 10.1016/j.fsigen.2008.07.001

Goudet J. 1995. FSTAT version 1.2: a computer program to calculate F-statistics. Journal of Heredity 86:485-486.

Haken J. 2011. Transnational crime in the developing world. Washington DC: Global Financial Integrity.

Hughes CR, Melland RR, and Beissinger SR. 1998. Polymorphic trinucleotide microsatellite loci for a neotropical parrot, the green-rumped parrotlet, Forpus passerinus. Molecular Ecology 7:1247-1248.

IUCN. 2015. The IUCN Red List of Threatened Species. Available at http://www.iucnredlist.org.

Iyengar A. 2014. Forensic DNA analysis for animal protection and biodiversity conservation: A review. Journal for Nature Conservation 22:195-205. 10.1016/j.jnc.2013.12.001

Johnson RN, Wilson-Wilde L, and Linacre A. 2014. Current and future directions of DNA in wildlife forensic science. Forensic Science International-Genetics 10:1-11. 10.1016/j.fsigen.2013.12.007

Kalinowski ST, Taper ML, and Marshall TC. 2007. Revising how the computer program CERVUS accommodates genotyping error increases success in paternity assignment. Molecular Ecology 16:1099-1106. 10.1111/j.1365-294X.2007.03089.x

Linacre A, Gusmao L, Hecht W, Hellmann AP, Mayr WR, Parson W, Prinz M, Schneider PM, and Morling N. 2011. ISFG: Recommendations regarding the use of non-human (animal) DNA in forensic genetic investigations. Forensic Science International-Genetics 5:501505. 10.1016/j.fsigen.2010.10.017

Ogden R, Dawnay N, and McEwing R. 2010. Wildlife DNA forensics-bridging the gap between conservation genetics and law enforcement. Endangered Species Research 9:179-195. 10.3354/esr00144

Peakall R, and Smouse PE. 2006. GENALEX 6: genetic analysis in Excel. Population genetic software for teaching and research. Molecular Ecology Notes 6:288-295. 10.1111/j.14718286.2005.01155.x

Presti FT, and Wasko AP. 2014. A review of microsatellite markers and their application on genetic diversity studies in parrots. Open Journal of Genetics 4:69-77.

Ringler E. 2012. The use of cross-species testing of microsatellite markers and sibship analysis in ex situ population management. Conservation Genetics Resources 4:815-819. 10.1007/s 12686-012-9642-5

South N, and Wyatt T. 2011. Comparing Illicit Trades in Wildlife and Drugs: An Exploratory Study. Deviant Behavior 32:538-561. Pii 938724995

10.1080/01639625.2010.483162

UNEP-WCMC. 2015. The Checklist of CITES Species Website. Available at http://checklist.cites.org/. 
241 Van Oosterhout C, Hutchinson WF, Wills DPM, and Shipley P. 2004. MICRO-CHECKER: 242 software for identifying and correcting genotyping errors in microsatellite data. $243 \quad$ Molecular Ecology Notes 4:535-538. 10.1111/j.1471-8286.2004.00684.x

244 White NE, Dawson R, Coghlan ML, Tridico SR, Mawson PR, Haile J, and Bunce M. 2012. 245 Application of STR markers in wildlife forensic casework involving Australian blackcockatoos (Calyptorhynchus spp.). Forensic Science International-Genetics 6:664-670. 10.1016/j.fsigen.2011.10.003 